\title{
Assessment of Stress in Anesthesiologists Using Heart Rate Variability during Anesthetic Induction: An Observational Study
}

\author{
Toshiyuki Sawai, Junko Nakahira*, Shoko Nakano, Ryosuke Mihara, Toshiaki Minami \\ Department of Anesthesiology, Osaka Medical College, Takatsuki, Japan
}

*Corresponding Author: Junko Nakahira, Department of Anesthesiology, Osaka Medical College, Takatsuki, Japan,Email: ane052@osaka-med.ac.jp

\begin{abstract}
Background: Anesthesiologists often experience work-related stress. No studies have used heart rate variability (HRV), an objective indicator of autonomic nervous system activity, to measure stress in anesthesiologists. Using the maximum entropy method, we measured HRV to assess the degree of stress in anesthesiologists while performing anesthetic induction.
\end{abstract}

Methods: Four anesthesiologists performed several anesthetic inductions while sitting and standing. Precordial electrocardiography was analyzed. The anesthesiologists' heart rate, ultra-short-term entropy low- and high-frequency components, and normalized unit of the low-frequency component (NU) were measured throughout and during different parts of anesthetic induction.

Results: Throughout anesthetic induction, the NU was only parameter that significantly differed between sitting and standing. Two-way repeated ANOVA showed a significant difference only in the average NU between the two groups $(P=0.018$ for the average $N U, P=0.088$ for the maximum $N U)$. Comparison between the standing and sitting groups showed that the $N U$ was significantly higher during endotracheal intubation in the standing position. During endotracheal intubation, the average $N U$ in the standing group was $87.1 \% \pm 4.7 \%$, whereas that in the sitting group was $78.1 \% \pm 8.8 \%(P=0.0042)$. The heart rate was significantly higher during intubation than during preoxygenation while both sitting and standing.

Conclusions Anesthesiologists exhibited significantly higher sympathetic tone as measured using HRV during tracheal intubation than during other parts of anesthetic induction. This sympathetic tone was higher while standing than sitting. Sitting during anesthetic procedures might reduce stress in anesthesiologists.

Keywords: heart rate variability, maximum entropy method, sympatho-parasympathetic balance, anesthesiologists.

Abbreviations: high-frequency $(H F)$, heart rate variability $(H R V)$, low-frequency $(L F)$, normalized unit of the low-frequency component (NU), Two-way repeated measure of analysis of variance (ANOVA), ultrashort-term entropy (UsEn)

\section{INTRODUCTION}

Operative procedures vary widely and full concentration is needed for long periods of time. Anesthesiologists, including trainees and instructors, are therefore becoming increasingly stressed and exhausted. Stress is a physical and psychological response to environmental demands. Burnout of anesthesiologists is not rare [1-3]. Maintenance of anesthesiologists' mental health has become a major concern that has been frequently reported and discussed throughout Japan [1-11].

Many studies have evaluated stress in anesthesiologists using self-reported questionnaires including the 20-item Multidimensional Fatigue Inventory and the 12-item General Health
Questionnaire, which are used to assess workrelated exhaustion and mental health, respectively; the work stress score; and other questionnaires [711]. Because stress results from the combination of the individual's circumstances and psychological status, scientific evaluation of stress is difficult. Some studies have evaluated decreases in blood pressure and changes in the salivary cortisol concentration as markers of fatigue and sleep deprivation in staff anesthesiologists [12, 13], and other have used a flicker photometer and stabilometer[14] and Holter electrocardiography [15]. We believe that the most practical method with which to evaluate stress is evaluation of the autonomic nervous system. Heart rate variability (HRV) enables objective evaluation of autonomic function [16-18]. 
HRV analysis is a noninvasive technique used to provide information about the autonomic nervous system [19]. This technique provides important information about the autonomic and central nervous systems because variations in the heart rate are mediated by central and peripheral neural mechanisms [20]. Frequency analysis of an R-R interval time series using the maximum entropy method, fast Fourier transform, or an autoregressive model enables estimation of the spectral power in milliseconds squared [21]. The low-frequency(LF) component $(0.05-0.15 \mathrm{~Hz})$ is influenced by sympathetic and parasympathetic activities, and the high-frequency (HF) component $(0.15-0.50$ $\mathrm{Hz}$ ) originates from parasympathetic activity. The LF component is thought to increase in response to sympathetic activity, and the HF component is thought to increase in response to vagal tone [22-25]. Generally, activation of the parasympathetic nervous system is evaluated as the HF component, and activation of the sympathetic nervous system is evaluated as the normalized unit of the LF component (NU) or the LF/HF ratio [22-26]. These are considered to be the most sensitive markers of the overall balance of sympathetic tone. The NU is calculated by multiplying the power of the LF component by 100 and then dividing this value by the sum of the power of the LF and HF spectra $[27,28]$.

The overall activity of the autonomic nervous system is complicated because it is influenced by many factors. However, measurement of HRV allows us to make judgments about the balance between sympathetic and parasympathetic activity. We hypothesized that this technique can be used to evaluate stress in anesthesiologists.

\section{Materials AND Methods}

\subsection{Study Protocol}

This study was approved by the ethics committee of Osaka Medical College, Osaka, Japan (approval no. 1520 Eki-2). This study has been registered as a clinical study in the Japanese official Clinical Trial Registry (trial registration no. JMA-IIA00185). All study participants provided written informed consent before participation. Four healthy anesthesiologists with normal sinus rhythm were enrolled in the study. All were certified as qualified anesthesia instructors from one institution in Japan. None of the participants were using medications that affect the heart rate, and none had preexisting cardiac disease, including arrhythmias. The youngest participant was a 32-year-old woman with 6 years of experience in anesthesiology, and the second youngest was a 34-year-old man with 8 years of experience. The second oldest participant was a 37-year-old woman with 12 years of experience, and the oldest was a 42year-old man with 17 years of experience. None of the participants had taken part in any vigorous activity within $30 \mathrm{~min}$ of the control recording, and they had not consumed caffeine on the day of the study. Each participant performed anesthetic induction three times in the standing position and three times in the sitting position, and data were obtained from 8:00 AM to 3:00 PM. In both the sitting and standing positions, the height of the operating table was adjusted so that the patient's forehead was placed at the level of the anesthesiologist's xiphoid process before induction of anesthesia. Each participant's electrocardiogram was transferred from a small wireless transmitter attached to the left precordia. The data were received by and recorded in a computer with software that analyzes HRV in real time (MemCalc/Bonaly Light ${ }^{\circledR}$; GMS, Tokyo, Japan). The transmitter weighed $15 \mathrm{~g}$ and was $41 \mathrm{~mm}$ high, $44 \mathrm{~mm}$ long, and $9.7 \mathrm{~mm}$ wide (Figure1). Precordial electrocardiography was analyzed for 30 sto calculate the HF and LF components, and the data were updated every2 s. Data are expressed as the power spectral density of the LF and HF components and the NU.

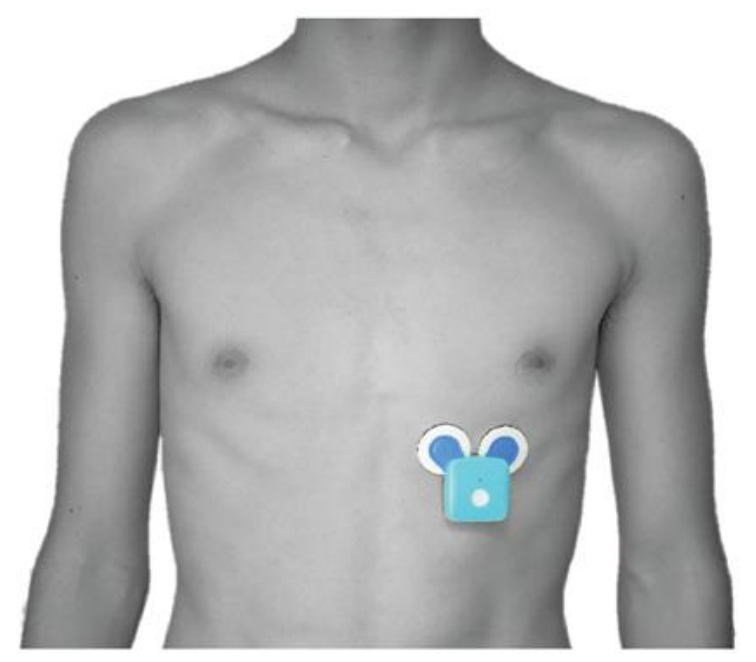

Figure1. Wireless transmitter

Induction of anesthesia was performed on patients with no estimated airway management difficulty. At the time of induction, a staff nurse placed an oxygen mask on the patient, and one of the study staff members administered the anesthetic medication so that the participants 
were able to concentrate on managing the patient's airway. After the patients had been oxygenated with the mask, the participants performed endotracheal intubation with a laryngoscope. An assistant recorded when each task started and ended. Each task was recorded as an event mark on the computer. For the anesthetic induction, propofol, remifentanil, and rocuronium were given intravenously and sevoflurane was simultaneously administered by inhalation. The process of anesthetic induction was divided into six sections (Table 1). In Section 0, a staff nurse provided oxygen through the face mask while the anesthesiologist stood near the operation table. This was the control recording. Section 1 was the period from anesthetic agent administration to the beginning of bag-mask ventilation. Section 2 was the period from the beginning of ventilation to administration of the neuromuscular blockade. Section 3 was the period from opening of the patient's mouth for laryngoscopy to placement of the endotracheal tube. Section 4 was the period of endotracheal tube insertion. Finally, Section 5 comprised the first $60 \mathrm{~s}$ of manual ventilation after intubation. If the participants failed to perform adequate airway management including insertion of the endotracheal tube, the study was stopped and the case was excluded. A trial of intubation was counted as a failure of intubation if a second trial was needed for any reason.

Induction of anesthesia was performed on patients with no estimated airway management difficulty.
At the time of induction, a staff nurse placed an oxygen mask on the patient, and one of the study staff members administered the anesthetic medication so that the participants were able to concentrate on managing the patient's airway. After the patients had been oxygenated with the mask, the participants performed endotracheal intubation with a laryngoscope. An assistant recorded when each task started and ended. Each task was recorded as an event mark on the computer. For the anesthetic induction, propofol, remifentanil, and rocuronium were given intravenously and sevoflurane was simultaneously administered by inhalation. The process of anesthetic induction was divided into six sections (Table 1). In Section 0, a staff nurse provided oxygen through the face mask while the anesthesiologist stood near the operation table. This was the control recording. Section 1 was the period from anesthetic agent administration to the beginning of bag-mask ventilation. Section 2 was the period from the beginning of ventilation to administration of the neuromuscular blockade. Section 3 was the period from opening of the patient's mouth for laryngoscopy to placement of the endotracheal tube. Section 4 was the period of endotracheal tube insertion. Finally, Section 5 comprised the first $60 \mathrm{~s}$ of manual ventilation after intubation. If the participants failed to perform adequate airway management including insertion of the endotracheal tube, the study was stopped and the case was excluded. A trial of intubation was counted as a failure of intubation if a second trial was needed for any reason.

Table1: Six sections of anesthetic induction

\begin{tabular}{|l|l|}
\hline Section & \\
\hline 0 (control) & Oxygenation of patient through face mask provided by staff nurse \\
\hline 1 & From anesthetic agent administration to beginning of bag-mask ventilation \\
\hline 2 & From beginning of ventilation to neuromuscular blockade administration \\
\hline 3 & From opening of patient's mouth for laryngoscopy to receiving the endotracheal tube \\
\hline 4 & Insertion of endotracheal tube \\
\hline 5 & First 60 s of manual ventilation after intubation \\
\hline
\end{tabular}

\subsection{Data Analysis}

Data were first tested for normal distribution using the Shapiro-Wilks test. The MannWhitney $\mathrm{U}$ test was then used to analyze nonnormally distributed parameters, and the unpaired Student's $t$-test was used to analyze normally distributed parameters. Hence, the Student's $t$-test was used to analyze differences between the two groups in minimum HR, mean $\mathrm{HR}$, maximum HR, UsEn and NU, and the Mann-Whitney $U$ test was used to analyze differences between the two groups in LF and
HF. Two-way repeated measure of analysis of variance (ANOVA) was used for the time course between the standing and sitting groups. Paired $t$-testing was done for each time point. Data are expressed as mean \pm standard deviation. All statistical analyses were performed by Graph Pad Prism 5 software (Graph Pad Software, La Jolla, CA). AP value of $<0.05$ was considered statistically significant.

\section{RESUlts}

Eleven cases in the standing position and 12 cases in the sitting position were analyzed. One 
case of standing was excluded from the study because of an error involving the transmitter. The present study was the first time for all four anesthesiologists to perform anesthetic induction while sitting. No cases were excluded because of airway management failure at the first trial.

Table 2 shows the results that were calculated as averages over the entire period of anesthetic induction. The only parameter that significantly differed between the two groups was the NU.

As shown in Figure 2, two-way repeated ANOVA showed significant differences in the average NU between the two groups $(P=$ 0.001 for the average NU, $P=0.088$ for the maximum NU). Furthermore, comparison between the standing and sitting groups showed

Table2: Comparison of the average values in the entire anesthetic time

\begin{tabular}{|l|l|l|l|}
\hline & Standing group & Sitting group & $P$ value \\
\hline Min HR (bpm) & $82.7 \pm 7.0$ & $85.0 \pm 12.9$ & 0.6041 \\
\hline Mean HR (bpm) & $85.7 \pm 6.4$ & $87.9 \pm 12.2$ & 0.5951 \\
\hline Max HR (bpm) & $89.0 \pm 5.7$ & $91.1 \pm 11.4$ & 0.5883 \\
\hline UsEn (\%) & $44.3 \pm 7.6$ & $45.4 \pm 10.0$ & 0.7656 \\
\hline LF (ms2) & $376.0 \pm 271.3$ & $303.4 \pm 284.4$ & 0.6891 \\
\hline HF (ms2) & $77.4 \pm 66.3$ & $99.5 \pm 83.6$ & 0.6444 \\
\hline NU (\%) & $80.3 \pm 4.4$ & $75.1 \pm 6.7$ & $0.0398^{*}$ \\
\hline
\end{tabular}

Min: minimum, Max, maximum, HR: heart rate, UsEn: ultra-short-term entropy, LF: low-frequency component, $H F$ : high-frequency component, $N U$ : normalized unit.

Data are expressed as mean \pm standard deviation. $* P<0.05$ is statistically significant.

a

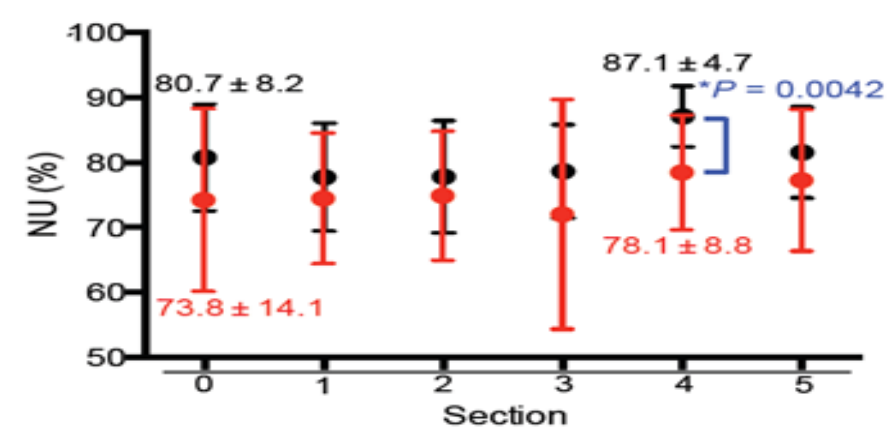

b

Maximum NU

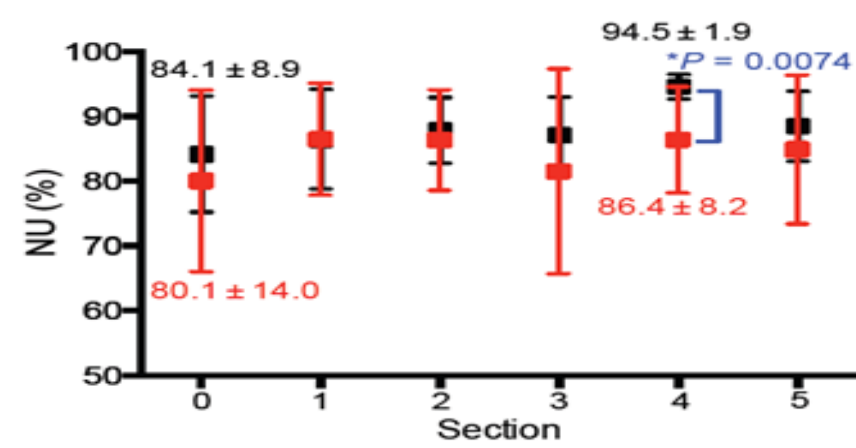

- Standing

- Sitting that the NU was significantly higher in Section $86.4 \% \pm 8.2 \%(P=0.0074)$.

Comparison of the average and maximum heart rate in each section between the two groups is two groups $(P=0.587$ for the average heart rate $P=0.483$ for the maximum heart rate). There were no significant differences in the average and maximum heart rate at each time point between the two groups. 
way repeated ANOVA showed a significant difference only in the average $N U$ between the two groups $(P=$ 0.018 for the average $N U$, and $P=0.088$ for the maximum $N U)$. $P$ values were obtained using the paired Student's t-test at each time point. In section 4, the average and maximum NU in the standing group were higher than those in the sitting group.

a

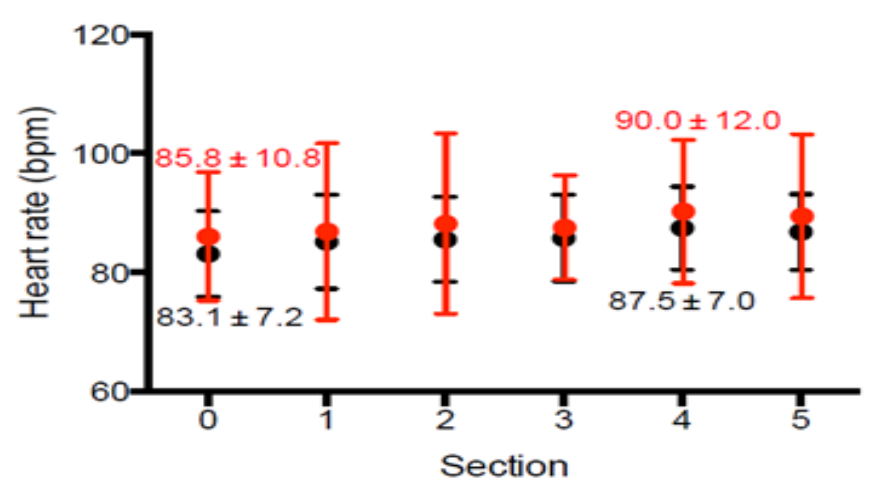

b

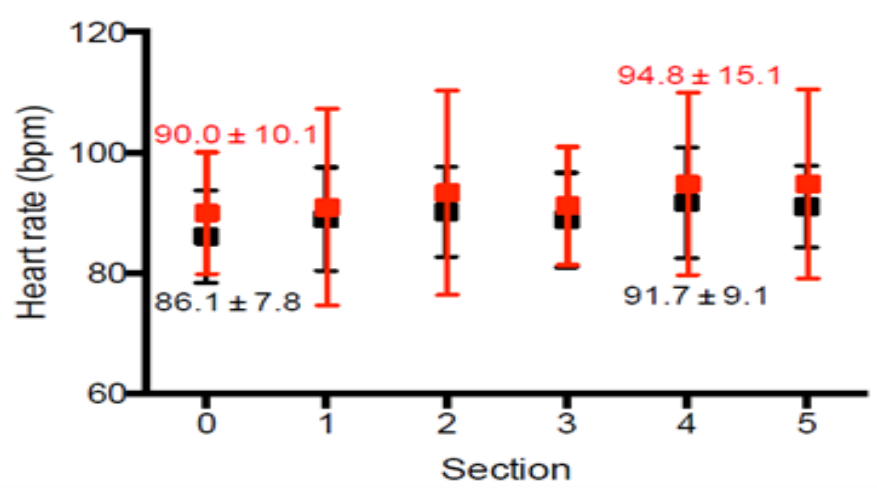

- Standing Sitting

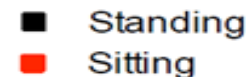

Figure3. Results of heart rate measurement. a: Average heart rates in each section. $b$ : Maximum heart rates in each section. Data are expressed as mean \pm standard deviation. Paired Student's t-test results at each time point showed no significant differences between the two groups. Two-way repeated ANOVA showed no significant differences between the two groups $(P=0.587$ for the average heart rate, $P=0.483$ for the maximum heart rate).

\section{DISCUSSION}

This study demonstrated a significant increase in sympathetic tone, measured using HRV, in experienced and certified anesthesiologists during endotracheal tube insertion at the time of anesthetic induction. Interestingly, at the time of endotracheal tube insertion, the sympathetic tone was higher in the standing than sitting position. Stress is routinely encountered as part of a clinician's daily work. Importantly, stress has a direct impact on performance and decision-making; an appropriate level of stress improves performance, but an excessive level of stress leads to poorer performance and decisionmaking [32, 33]. Some reports have demonstrated the relationship between performance and stress in surgeons [17, 34-37]; however, no studies have used HRV to evaluate stress in anesthesiologists. Evidence of the effects of the occupational environment on mental strain experienced by anesthesiologists has been increasing in recent years, similar to previous studies that found an increase in sympathetic tone in surgeons as assessed using HRV [17, 34-36]. Jones et al. [34] demonstrated a significant increase in sympathetic tone by measurement of HRV in consultant surgeons during the performance of elective colorectal resection. They reported that the highest $\mathrm{LF} / \mathrm{HF}$ ratio during the surgery occurred during mesorectal dissection. Some studies in the field of anesthesia have investigated autonomic function in patients using HRV analysis [26, 30, 39 , 40]. However, this is the first study to evaluate the sympatho-parasympathetic balance in anesthesiologists and investigate the possibility of measuring stress in anesthesiologists by short-term fractal measurement of HRV.

Analysis of HRV in all stages of anesthetic induction in the present study revealed that the highest NU occurred during insertion of the 
endotracheal tube in both the standing and sitting position. We also compared the difference in the NU during anesthetic induction between the sitting and standing positions and found that the average NU during insertion was significantly higher in the standing position. This may indicate that the sympathetic tone was lower in the sitting than standing position. Although tracheal tube insertion is a small part of anesthetic induction, anesthesiologists perform the insertion many times while working. Use of the sitting position during anesthetic procedures such as venous and arterialcannulation might reduce stress in anesthesiologists.

Spectral analysis of HRV is widely accepted as a noninvasive technique for assessment of the autonomic control of the heart [21]. Although there is some controversy in terms of interpretation, it is generally agreed that the NU represents the balance between the sympathetic and parasympathetic parts of the autonomic nervous system. The LF component reflects sympathetic and vagal nerve activity, and the HF component represents vagal nerve activity [26]. In this study, we used the maximum entropy method because our data covered a short period. With this method, we calculated the LF and HF components using $30 \mathrm{~s}$ of electrocardiogram data with updates every $2 \mathrm{~s}$. We were therefore able to automatically eliminate irregular heartbeats. Another advantage of using the MemCalc/BonalyLight ${ }^{\circledR}$ was the small wireless transmitter, which prevented movement limitations in the participants. This system enabled us to evaluate the sympatho-parasympathetic balance. However, two technical issues were not resolved during this study. First, each NU value might have contained the NU values from the former section because although the NU was calculated using data covering $30 \mathrm{~s}$, each section of anesthetic induction covered only a short period of time. Second, respiratory arrhythmias and oscillations were influenced by the respiratory rate and tidal volume because the change in intrathoracic pressure caused by breathing causes variations in the heart rate via the parasympathetic nervous system [41].

In their clinical practice, all four anesthesiologists performed anesthetic induction while standing. The present study was the first time for all four anesthesiologists to perform anesthetic induction while sitting. In spite of this, the results indicate that anesthetic induction in the sitting position was less stressful for the anesthesiologists. This finding is particularly notable because it may indicate that anesthetic induction performed while seated may increase sympathetic activity (because it was the first time for the anesthesiologists).

There were several study limitations. First, as described above, the NU values might have included data from the former section. Second, the participants were of different ages and both sexes. HRV decreases with age $[22,42,43]$ and is lower in males than females [26, 44]. This might have influenced the results, and further studies that control for age and sex are needed. We also did not include a control group of anesthesiologists who sat and stood for the same lengths of time but without managing a patient's airway. Section 0, which was the period of patient oxygenation, was used as the control in this study; however, the period of time before the patients entered the operating room may have been a more effective control.

Spectral analysis of HRV is widely accepted as a noninvasive technique for assessment of the autonomic control of the heart [21]. Although there is some controversy in terms of interpretation, it is generally agreed that the NU represents the balance between the sympathetic and parasympathetic parts of the autonomic nervous system. The LF component reflects sympathetic and vagal nerve activity, and the HF component represents vagal nerve activity [26]. In this study, we used the maximum entropy method because our data covered a short period. With this method, we calculated the LF and HF components using $30 \mathrm{~s}$ of electrocardiogram data with updates every $2 \mathrm{~s}$. We were therefore able to automatically eliminate irregular heartbeats. Another advantage of using the MemCalc/BonalyLight ${ }^{\circledR}$ was the small wireless transmitter, which prevented movement limitations in the participants. This system enabled us to evaluate the sympathoparasympathetic balance. However, two technical issues were not resolved during this study. First, each NU value might have contained the NU values from the former section because although the NU was calculated using data covering $30 \mathrm{~s}$, each section of anesthetic induction covered only a short period of time. Second, respiratory arrhythmias and oscillations were influenced by the respiratory rate and tidal volume because the change in intrathoracic pressure caused by breathing causes variations in the heart rate via the parasympathetic nervous system [41]. 
In their clinical practice, all four anesthesiologists performed anesthetic induction while standing. The present study was the first time for all four anesthesiologists to perform anesthetic induction while sitting. In spite of this, the results indicate that anesthetic induction in the sitting position was less stressful for the anesthesiologists. This finding is particularly notable because it may indicate that anesthetic induction performed while seated may increase sympathetic activity (because it was the first time for the anesthesiologists).

There were several study limitations. First, as described above, the NU values might have included data from the former section. Second, the participants were of different ages and both sexes. HRV decreases with age [22, 42, 43] and is lower in males than females [26, 44]. This might have influenced the results, and further studies that control for age and sex are needed. We also did not include a control group of anesthesiologists who sat and stood for the same lengths of time but without managing a patient's airway. Section 0, which was the period of patient oxygenation, was used as the control in this study; however, the period of time before the patients entered the operating room may have been a more effective control.

\section{CONCLUSION}

This study demonstrated a significant increase in sympathetic tone as measured using HRV in experienced anesthesiologists during the tracheal intubation portion of anesthetic induction. Furthermore, the sympathetic tone was higher when the anesthesiologists were standing than when they were sitting. This study method may be used in future research to assess the impact of stress on anesthesiologists' performance and approaches to training and anesthetic procedures.

\section{ACKNOWLEDGEMENT}

\section{Clinical Trial Number and Registry URL}

This study was registered as a clinical study in the Japanese Official Clinical Trial Registry (trial registration number: JMA-IIA00185, registry

URL:https://dbcentre3.jmacct.med.or.jp/JMACT R/App/JMACTRE02_04/JMACTRE02_04.aspx $? \mathrm{kbn}=3 \&$ seqno $=4522$ ).

\section{Authors' Contributions}

TS designed and carried out the study, and drafted the manuscript. JN collected the data, performed the statistical analysis, and helped to draft the manuscript. SN and RM participated in the design of the study and collected the data. TM conceived of the study, participated in its design and coordination, and helped to draft the manuscript. All authors read and approved the final manuscript.

\section{REFERENCES}

[1] Freire PL, Trentin JP, de Avila Quevedo L.: Trends in burnout syndrome and emotional factors: an assessment of anesthesiologists in Southern Brazil, 2012; Psychol Health Med. 2016 Vol21, No4; PP 413-423

[2] Misiołek A, Gil-Monte PR, Misiołek H. Prevalence of burnout in Polish anesthesiologists and anesthetist nursing professionals: A comparative non-randomized cross-sectional study; J Health Psychol. 2017 Vol.22, No.4; PP 465-474

[3] Shams T, El-Masry R. Job Stress and Burnout among Academic Career Anaesthesiologists at an Egyptian University Hospital. Sultan QaboosUniv Med J; 2013 Vol.13, No.2; PP 287-295

[4] Andrade GO, Dantas RA. Work-related mental and behaviour disorders in anesthesiologists; Braz J Anesthesiol. 2015 Vol.65, No.6; PP 504510

[5] Moore R, Gupta P, Duval Neto GF. Occupational fatigue: Impact on anesthesiologist's health and the safety of surgical patients; Braz J Anesthesiol. 2013 Vol.63, No.2; PP 167-169

[6] Gurman GM, Klein M, Weksler N. Professional stress in anesthesiology: a review; J ClinMonit Comput. 2012 Vol.26, No.4; PP 329-335

[7] Riad W, Mansour A, Moussa A. Anesthesiologists work-related exhaustion: A comparison study with other hospital employees; Saudi J Anaesth. 2011 Vol.5, No.3; PP 244-247

[8] Andrade AN, de Albuquerque MA, Andrade AN. Assessment of the stress level of anesthesiologists of the Sergipe anesthesiologists cooperative; Rev Bras Anestesiol. 2011 Vol.61, No.4; PP 486-494

[9] Mansour A, Riad W, Moussa A. The occupational fatigue in anesthesiologists: illusion or real?; Middle East J Anaesthesiol. 2010 Vol.20, No.4; PP 529-534

[10] Kawasaki K, Sekimoto M, Ishizaki T, Imanaka Y. Work stress and workload of full-time anesthesiologists in acute care hospitals in Japan; J Anesth. 2009 Vol.23, No.2; PP 235241

[11] Kinzl JF, Traweger C, Trefalt E, Riccabona U, Lederer W. Work stress and gender-dependent 
coping strategies in anesthesiologists at a university hospital; J ClinAnesth. 2007 Vol.19, No.5; PP 334-338

[12] Klein M, Weksler N, Gidron Y, Heldman E, Gurski E, Smith OR, Gurman GM. Do waking salivary cortisol levels correlate with anesthesiologist's job involvement?; J ClinMonitComput. 2012 Vol.26, No.6; PP 407413

[13] Carev M, Karanović N, Bagatin J, Matulić NB, Pecotić R, Valić M, Marinović-Terzić I, Karanović S, Dogas Z. Blood pressure dipping and salivary cortisol as markers of fatigue and sleep deprivation in staff anesthesiologists; CollAntropol. 2011 Vol.35,No.1; PP 133-138

[14] Sato O, Kawabata H, Watanabe H, Kohro S, Omote K, Namiki A, Kishi R. Fatigue and stress of anesthesiologists at work--third report: investigation with a flicker photometer and a stabilo-meter (in Japanese with English abstract); Masui (Jpn JAnesthesiol). 1995 Vol.44, No.5; PP 674-678

[15] Kawabata H, Sato O, Watanabe H, Kishi R, Nagao K, Namiki A. Studies on fatigue and stress of anesthesiologist during anesthetic works using Holter ECG (in Japanese with English abstract); Masui (Jpn J Anesthesiol). 1993 Vol.42, No.11; PP 1699-1703

[16] Sgoifo A, Carnevali L, Alfonso Mde L, Amore M. Autonomic dysfunction and heart rate variability in depression; Stress. 2015 Vol.18, No.3; PP 343-352

[17] Prichard RS, O’Neill CJ, Oucharek JJ, Holmes CY, Delbridge LW, Sywak MS. A prospective study of heart rate variability in endocrine surgery: surgical training increases consultant's mental strain; J Surg Educ. 2012 Vol.69, No.4 ; PP 453-458

[18] deVente W, van Amsterdam JG, Olff M, Kamphuis JH, Emmelkamp PM. Burnout Is Associated with Reduced Parasympathetic Activity and Reduced HPA Axis Responsiveness, Predominantly in Males; Biomed Res Int. 2015 Vol.2015, No.431725; PP 1-13

[19] Task Force of the European Society of Cardiology and the North American Society of Pacing and Electrophysiology. Heart rate variability. Standards of measurement, physiological interpretation, and clinical use; Eur Heart J. 1996 Vol.17, No.3; PP 354-381

[20] Malliani A, Pagani M, Lombardi F, Cerutti S. Cardiovascular neural regulation explored in the frequency domain; Circulation. 1991 Vol.84, No.2; PP 482-492

[21] Akselrod S, Gordon D, Ubel FA, Shannon DC, Berger AC, Cohen RJ. Power spectrum analysis of heart rate fluctuation: a quantitative probe of beat-to-beat cardiovascular control; Science.
1981 Vol.213, No.4054; PP 220-222

[22] Malik M. Task Force of the European Society of Cardiology and the North American Society of Pacing and Electrophysiology.Heart rate variability; Circulation. 1996 Vol.93, No.5; PP 1043-1063

[23] Pagani M, Furlan R, Pizzinelli P, Crivellaro W, Cerutti S, Malliani A. Spectral analysis of R-R and arterial pressure variabilities to assess sympatho-vagal interaction during mental stress in humans; Hypertension. 1989 Vol.7, No.6; PP $14-15$

[24] Lin LY, Wu CC, Liu CC, Ho YB, Liau YL, Lee YT. Derangement of heart rate variability during a catastrophic earthquake: a possible mechanism for increased heart attacks; Pacing ClinElectrophysiol. 2001Vol.24, No.11; PP 1596-1601

[25] McCraty R, Atkinson M, Tiller AW, Rein G, Watkins AD. The effects of emotions on short term power spectrum analysis of heart rate variability; Am J Cardiol. 1995 Vol.76, No.14; PP 1089-1093

[26] Fujiwara Y, Kurokawa S, Asakura Y, Wakao Y, Nishiwaki K, Komatsu T. Correlation between heart rate variability and haemodynamic fluctuation during induction of general anaesthesia: comparison between linear and non-linear analysis; Anaesthesia. 2007 Vol.62, No.2; PP 117-121

[27] Huikuri HV, Pikkujämsä SM, Airaksinen KE, Ikäheimo MJ, Rantala AO, Kauma H, Lilja M, Kesäniemi YA. Sex-related differences in autonomic modulation of heart rate in middleaged subjects; Circulation. 1996 Vol.94, No.2; PP 122-125

[28] Pagani M, Montano N, Porta A, Malliani A, Abboud FM, Birkett C, and Somers VK. Relationship between spectral components of cardiovascular variabilities and direct measures of muscle sympathetic nerve activity in humans; Circulation. 1997 Vol.95, No.6; PP 1441-1448

[29] Arai YC, Nakayama M, Kato N, Wakao Y, Ito $\mathrm{H}$, Komatsu T. The effects of jaw thrust and the lateral position on heart rate variability in anesthetized children with obstructive sleep apnea syndrome; AnesthAnalg. 2007 Vol.104, No.6; PP 1352-1355

[30] Sawada Y, Ohtomo N, Tanaka Y, Tanaka G, Yamakoshi K, Terachi S, et al. New techinique for time series analysis combining the maximum entropy method and non-linear least squares method: its value in heart rate variability analysis; Med BiolEngComput. 1997 Vol.35, No.4; PP 318-322

[31] Win NN, Fukayama H, Kohase H, Umino M. The different effects of intravenous propofol and midazolam sedation on hemodynamic and 
heart rate variability; AnesthAnalg2005 Vol.101, No.1; PP 97-102

[32] Wetzel CM, Black SA, Hanna GB, Athanasiou T, Kneebone RL, Nestel D, Wolfe JH, Woloshynowych M. The effects of stress and coping on surgical performance during simulations; Ann Surg. 2010 Vol.251, No.1; PP 171-176

[33] Hassan I, Weyers P, Maschuw K, Dick B, Gerdes B, Rothmund M, Zielke A. Negative stress-coping strategies among novices in surgery correlate with poor virtual laparoscopic performance; Br J Surg. 2006 Vol.93, No.12; PP 1554-1559

[34] Jones KI, Amawi F, Bhalla A, Peacock O, Williams JP, Lund JN. Assessing surgeon stress when operating using heart rate variability and the State Trait Anxiety Inventory: will surgery be the death of us?; Colorectal Dis. 2015 Vol.17, No.4; PP 335-341

[35] Böhm B, Rötting N, Schwenk W, Grebe S. A prospective randomized trial on heart rate variability of the surgical team during laparoscopic and conventional sigmoid resection; Arch Surg. 2001 Vol.136, No.3; PP 305-310

[36] Langelotz C, Scharfenberg M, Haase O, Schwenk W. Stress and heart rate variability in surgeons during a 24-hour shift; Arch Surg. 2008 Vol.143, No.8; PP 751-755

[37] Amirian I, Toftegård Andersen L, Rosenberg J,Gögenur I. Decreased heart rate variability in surgeons during night shifts; Can J Surg. 2014 Vol.57, No.3; PP 300-304

[38] Demirtas Y, Tulmac ,Yavuzer R, Yalcin R, Ayhan S, Latifoglu O, Atabay K. Plastic surgeon's life: marvelous for mind, exhausting for body; PlastReconstr Surg. 2004 Vol.114, No.4;PP 923-931

[39] Schumacher A. Linear and nonlinear approaches to the analysis of R-R interval variability; Biol Res Nurs. 2004 Vol.5, No.3; PP 211-221

[40] Kanaya N, Hirata N, Kurosawa S, Nakayama M, Namiki A. Differential effects of propofol and sevoflurane on heart rate variability; Anesthesiology. 2003 Vol.98, No.1; PP 34-40

[41] Yasuma F, Hayano J. Respiratory sinus arrhythmia: why does the heartbeat synchronize with respiratory rhythm?; Chest. 2004 Vol.125, No.2; PP 683-690

[42] Shannon DC, Carley DW, Benson H. Aging of modulation of heart rate; Am J Physiol. 1987 Vol.253, No.4; PP H874-877

[43] Föhr T, Tolvanen A, Myllymäki T, JärveläReijonen E, Rantala S, Korpela R, Peuhkuri K, Kolehmainen M, Puttonen S, Lappalainen R, Rusko H, Kujala UM. Subjective stress, objective heart rate variability-based stress, and recovery on workdays among overweight and psychologically distressed individuals: a crosssectional study; J Occup Med Toxicol. 2015Vol.10; PP 39

[44] Pikkujämsä SM, Mäkikallio TH, Airaksinen KE, Huikuri HV. Determinants and interindividual variation of $\mathrm{R}-\mathrm{R}$ interval dynamics in healthy middle-aged subjects; Am J Physiol Heart Circ Physiol. 2001 Vol.280, No.3; PP 1400-1446

Citation: Toshiyuki Sawai, Junko Nakahira, Shoko Nakano, Ryosuke Mihara, Toshiaki Minami. Assessment of Stress in Anesthesiologists Using Heart Rate Variability during Anesthetic Induction: An Observational Study. ARC Journal of Anesthesiology. 2019; 4(1):1-9. DOI: dx.doi.org/10.20431/2455-9792.0401001.

Copyright: (C) 2019 Authors. This is an open-access article distributed under the terms of the Creative Commons Attribution License, which permits unrestricted use, distribution, and reproduction in any medium, provided the original author and source are credited. 